Thorax, 1979, 34, 501-507

\title{
Effect of ipratropium bromide on mucociliary clearance and pulmonary function in reversible airways obstruction
}

\author{
DEMETRI PAVIA, J RODERICK M BATEMAN, NOÍRÍN F SHEAHAN, \\ AND STEWART W CLARKE
}

From the Department of Thoracic Medicine, The Royal Free Hospital, London NW3 2QG, UK

\begin{abstract}
The effects of (a) regular use for one week and (b) a single dose of a synthetic anticholinergic (ipratropium bromide) on lung mucociliary clearance and as a bronchodilator was ascertained in a controlled, double-blind, cross-over study in 12 patients with reversible airways obstruction (mean increase in $\mathrm{FEV}_{1}$ after isoprenaline: $17 \%$, range $10-50 \%$ ). Two puffs from a metered dose inhaler of either placebo (propellants only) or drug (40 $\mu \mathrm{g})$ were administered four times a day for one week (regular use), and mucociliary clearance was measured, by radioaerosol tracer, at the end of each treatment period and after a control period in which no treatment was given. On the mornings of the measurements after the placebo and drug periods one final dose (single dose) of ipratropium $(40 \mu \mathrm{g})$ or placebo was given 2.5 hours before the start of the test. There was no statistically significant difference between the three mean mucociliary clearance curves (control, placebo, and drug) for the group; however, there was a significantly greater penetration towards the periphery of the lung of the tracer in the test after drug administration compared with the other two. This increased penetration was attributed to bronchodilatation caused by the drug. Ipratropium bromide does not appear to impair mucociliary clearance, and it acts as an effective bronchodilator.
\end{abstract}

Impairment of lung mucociliary clearance has been observed in man after administration of the anticholinergic drugs hyoscine (Pavia and Thomson, 1971) and atropine (Foster et al, 1976). Ipratropium bromide, chemically a quarternary ammonium compound, is a synthetic anticholinergic agent. It is known to be an effective bronchodilator (Poppius et al, 1972). In healthy volunteers Francis et al (1977) have shown that this agent did not impair mocociliary clearance for inhaled doses up to four times the recommended therapeutic dose $(40 \mu \mathrm{g})$. We report a controlled, double-blind cross-over study to ascertain the effect of (a) regular use (40 $\mu \mathrm{g}$ four times daily for seven days) and (b) a single dose $(40 \mu \mathrm{g})$ of ipratropium bromide (and of the propellants) on lung mucociliary clearance and on bronchodilatation in 12 patients with reversible airways obstruction.

\section{Methods}

PATIENTS

Twelve patients ( 10 men, 2 women) with reversible airways obstruction of $10 \%$ of baseline $\mathrm{FEV}_{1}$ or greater were studied. Table 1 summarises their physical characteristics, tobacco consumption, and ventilatory function. Informed, written consent was obtained from each patient. Ten had chronic obstructive bronchitis and two had in addition clinical features of asthma. Six of the patients were current smokers and the remaining six ex-

Table 1 Physical characteristics, tobacco consumption, and ventilatory capacity indices in 12 patients

\begin{tabular}{|c|c|}
\hline Characteristics & Results $($ mean $\pm S D)$ \\
\hline $\begin{array}{l}\text { Age (yr) } \\
\text { Height (m) } \\
\text { Tobacco consumption (pack years) } \\
\text { FEV } 1 \text { observed (1) } \\
\text { FEV } 1 \% \text { predicted* } \\
\text { FVC observed (1) } \\
\text { FVC \% predicted* } \\
\text { FEV } / \text { FVC observed }(\%) \\
\text { PEFR observed }\left(1 / \text { min }^{-1}\right) \\
\text { PEFR } \% \text { predicted* }\end{array}$ & $\begin{aligned} 63 & \pm 8 \\
1 \cdot 68 & \pm 0 \cdot 09 \\
64 & \pm 30 \\
1 \cdot 14 & \pm 0 \cdot 50 \\
42 & \pm 15 \\
2 \cdot 70 & \pm 0 \cdot 62 \\
76 & \pm 22 \\
41 & \pm 11 \\
163 & \pm 70 \\
34 & \pm 16\end{aligned}$ \\
\hline
\end{tabular}

*Cotes (1975). 
smokers. The diary cards showed that the level of tobacco consumption of the current smokers remained constant throughout the study.

The type of sputum produced by the patients during the clearance measurements was graded macroscopically according to the Medical Research Council (1965) criteria as follows: M1 (mucoid, white) in two patients; M2 (mucoid, white with a hint of yellow) in six patients; P1 (purulent, less than one-third yellow) in two patients; and P3, (purulent, more than two-thirds yellow) in the remaining two patients. The patients' mean $( \pm S D)$ percentage changes in forced expiratory volume in $1 \mathrm{sec}\left(\mathrm{FEV}_{1}\right)$ from baseline values after inhaling two puffs of isoprenaline $(1 \mathrm{mg})$ was $17( \pm 15 \%)$.

\section{EXPERIMENTAL DESIGN}

All treatment was discontinued for one week (washout period) before the first mucociliary clearance measurements and throughout the three weeks' trial period. Control measurements were performed after the washout period and then, in a random, double-blind manner, each of the patients was allotted placebo or drug treatment, half receiving each treatment first. The placebo consisted of propellants only; Freon 11, 12, and 114 in proportions $1: 2: 1$, plus soya lecithin surfactant. During the next seven days the treatment aerosols were self-administered from metered dose inhalers (dose: two puffs $=40 \mu \mathrm{g}$ of ipratropium bromide) four times a day at $0800,1200,1600$, and 2000.

The clearance measurements after placebo and drug were identical to the control determination, with the exception that final doses of both aerosols were inhaled about 2.5 hours before the inhalation of the radioaerosol.

The daily tobacco consumption (cigarettes a day) and the graded degree of shortness of breath and sputum production were recorded on a diary card by each patient daily for each of the three weeks. Peak expiratory flow rates (PEFR) on awakening (before treatment) and on retiring at night (two hours after last treatment) were also recorded on the cards.

Before the trial began patients underwent a two-day pilot study to ascertain that they responded to the bronchodilator action of the drug. In a double-blind, cross-over manner each of the 12 patients was allotted two puffs of placebo (propellants only) or drug at the same time of the day on two successive days. Their $\mathrm{FEV}_{1}, \mathrm{FVC}$, and PEFR were ascertained immediately before and after administration of the two puffs, and then at $15,30,60$, and 120 minutes. After this period the patients were administered two puffs of isoprenaline $(1 \mathrm{mg})$, irrespective of whether they were on placebo or drug, and its effect on the above lung function tests was measured. This established whether, at this time, their airways obstruction was maximally reversed by the ipratropium bromide.

\section{MEASUREMENT OF LUNG CLEARANCE BY}

RADIOAEROSOL

The method has been fully described by Thomson and Short (1969) and Thomson et al (1973). Uniform $5 \mu \mathrm{m}$ polystyrene particles were generated by a spinning disc (May, 1949) in an airtight tank, from which they were inhaled through the mouth by the seated patients. Inhalation (from the normal resting level of the lung) was auto- $\frac{\text { S }}{3}$ matically interrupted after a preset volume (here $\rightarrow$ 0.45 1) and was followed by an obligatory threesecond breath holding pause. The mean of the individual average inhalation flow rates, recorded $\stackrel{\oplus}{+}$ by a pneumotachygraph, were 33,32 , and $\vec{\theta}$

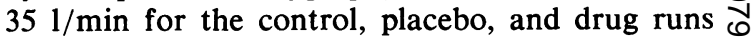
respectively. There were no statistically significant differences in this variable between any of the three runs. The particles were firmly labelled with ${ }^{90 \mathrm{~m}}$ technetium (Few et al, 1970), a gamma emitter of $6 \mathrm{~h}$ half-life, as tetraphenylarsonium pertechne- $\frac{\mathrm{O}}{\mathbb{D}}$ tate. The initial lung burden did not exceed $30 \mu \mathrm{Ci}$ of ${ }^{{ }^{90 m} \mathrm{Tc}}$ in any one run. The patients rinsed their mouths three times, and drank half a cup of water immediately after inhalation of the radioaerosol to remove any particles present in the oropharyngeal region and oesophagus. Clearance of the radioaerosol from the lungs was monitored by two opposing scintillation detectors (NaI(T1) crystals) suitably collimated (Thomson and Pavia, 1973). The anterior detector was applied closely to the midpoint of the sternum, and the posterior one to the spine axially opposite. Counts were taken for $100 \mathrm{~s}$ immediately after inhalation and at half-hourly intervals over six $\frac{7}{0}$ hours, and were corrected for radioactive background and decay.

The initial distribution of the deposited radio- $N$ aerosol across the right lung was determined by means of a rectilinear gamma scanner (Dawson $\omega$ et al, 1971). The detector traversed vertical columns at $2.5 \mathrm{~cm}$ intervals from the chest midline to the periphery. The detector was collimated by a cylindrical lead shield $(2.5 \mathrm{~cm}$ internal diameter $)$, which was extended $5 \mathrm{~cm}$ beyond the crystal face. The radioactive count for each traverse was $\overrightarrow{\mathbb{D}}$ displayed on a printer.

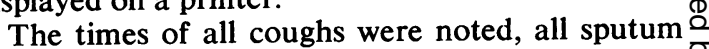
was collected as separate samples, and the total weight and radioactive content of the samples? was ascertained for each clearance measurement.? 
The patients did not smoke during the six-hour observation period, or for one hour before.

\section{PULMONARY FUNCTION TESTS}

The FEV $_{1}$ and FVC were measured by a dry bellows spirometer (Vitalograph) and the PEFR by a Wright peak flow meter. Throughout this study the highest reading was recorded out of three attempts for any one variable.

\section{STATISTICAL ANALYSIS}

The data of the variables measured in this study were not normally distributed, so the Wilcoxon test for pair differences (Snedecor and Cochran, 1968) has been used.

\section{Results}

\section{PULMONARY FUNCTION TESTS}

Figure 1 summarises the changes of the pulmonary function tests in the pilot study. The figure illustrates the mean values over a 120-min observation period of (a) PEFR, (b) FVC, and (c) $\mathrm{FEV}_{1}$ after two puffs of ipratropium bromide $(40 \mu \mathrm{g})$ or placebo and after two puffs of isoprenaline $(1 \mathrm{mg})$ given at $123 \mathrm{~min}$. There was no statistically significant difference between the mean baseline values for any of the three variables. From $15 \mathrm{~min}$ after inhalation onwards, however, all three variables were significantly higher $(P<0.01)$ after ipratropium bromide compared with placebo. Administration of isoprenaline resulted in a striking increase in all three variables after placebo, but no change was noted after ipratropium.

From the diary cards it was ascertained that the mean ( \pm SD) PEFRs in the mornings were 152 $( \pm 49), 148( \pm 49)$, and $161( \pm 61) 1 / \mathrm{min}$ in the control, placebo, and drug treatment periods (seven days) respectively. The mean PEFR in the drug period was significantly higher than that during administration of placebo $(P<0.05)$. The mean $( \pm \mathrm{SD})$ late evening PEFRs were 162 $( \pm 60), 156( \pm 47)$, and $186( \pm 84) 1 / \mathrm{min}$ for the control, placebo, and drug periods respectively. Here the PEFRs in the drug treatment period were statistically significantly higher than those in both the control $(P<0.01)$ and placebo $(P<0.05)$ periods.

Pulmonary function was assessed about 1.5 hours before inhaling the radioaerosol in each of the three administrations (table 2), that is, about one hour after the final dose of aerosol was inhaled after drug and placebo administration.

Both the $\mathrm{FEV}_{1}$ and FVCs were significantly higher on the days after administration of the
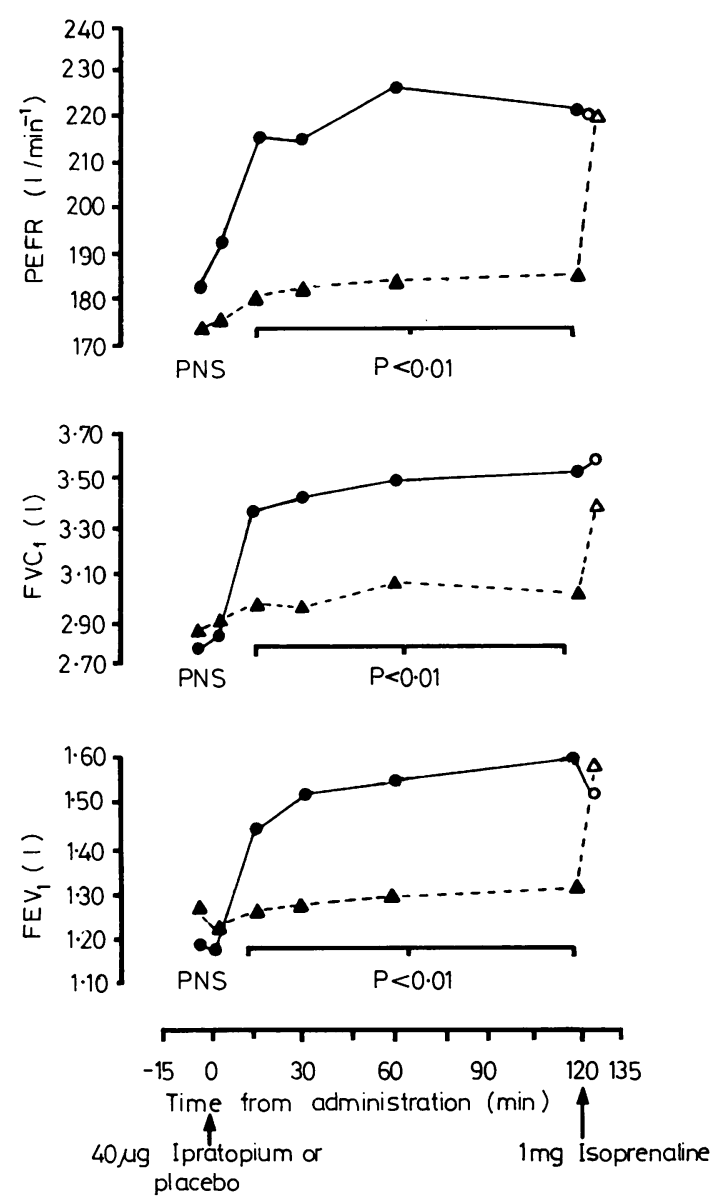

Fig 1 Mean changes of (a) PEFR, (b) FVC, and (c) FEV $V_{1}$ for 12 patients after inhalation of two puffs of ipratropium bromide, $40 \mathrm{mg}(\bullet)$, or placebo $(\Delta)$ at 0 min and two puffs of isoprenaline, $1 \mathrm{mg}(0, \Delta)$, at $123 \mathrm{~min}$.

Table 2 Mean $\pm S D, F E V_{1}$ and PEFR for 12 patients on the control, placebo, and drug mucociliary clearance measurements days

\begin{tabular}{llll}
\hline & $F E V_{1}(l)$ & $F V C(l)$ & PEFR $(l /$ min $)$ \\
\hline Control & $1 \cdot 14 \pm 0 \cdot 50 *$ & $2 \cdot 70 \pm 0 \cdot 62 \ddagger$ & $163 \pm 70 \ddagger$ \\
Placebo & $1 \cdot 16 \pm 0 \cdot 64 \ddagger$ & $2 \cdot 77 \pm 0 \cdot 82 \dagger$ & $176 \pm 74$ \\
Drug & $1 \cdot 40 \pm 0 \cdot 70^{*} \ddagger$ & $3 \cdot 32 \pm 1 \cdot 00 \dagger \ddagger$ & $197 \pm 91 \ddagger$ \\
\hline
\end{tabular}

Paired differences statistically significant at the $5 \%, 2 \% \dagger$, and $1 \%+$ levels.

drug compared with either the control or placebo days. The PEFRs, however, were only significantly higher on the drug days compared with the control days. 


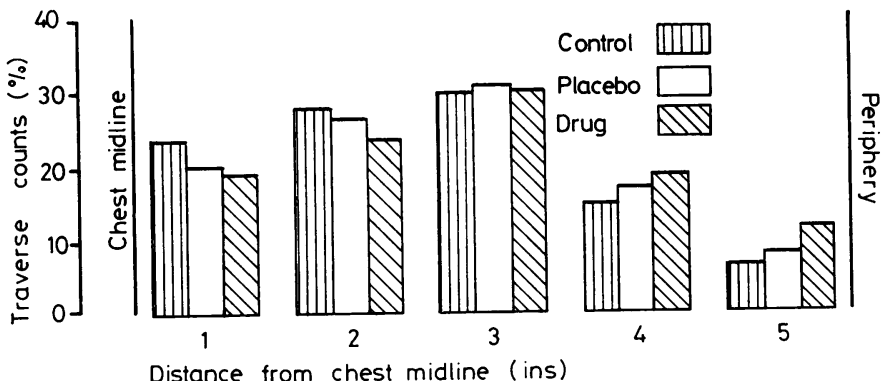

Distance from chest midline (ins)

\section{LUNG SCANS}

Figure 2 shows the initial lateral distribution of the radioaerosol across the right lung for the 12 patients on the control, placebo, and drug clearance measurement days. The counts in each traverse have been expressed as a percentage of the total scan count for each individual, and the mean percentage of all patients are shown as the height of the columns in fig 2. An index of penetration (Thomson and Pavia, 1974) has been used as a quantitative measure of the initial topographical distribution of the radioaerosol. This is obtained from the ratio of the sums of the counts of the outermost two traverses (nearest to the periphery) to those of the two innermost. The mean $\pm S D$ ratio for the drug runs, $0.75 \pm 0.41$, was significantly higher than that for the control runs, $0.41 \pm 0.23 \quad(\mathrm{P}<0.01)$ and placebo runs, $0.55 \pm 0.23(\mathrm{P}<0.05)$.

\section{LUNG CLEARANCE}

Figure 3 shows the mean $(n=12)$ clearance curves from whole lung counts at half-hourly intervals for the control, placebo, and drug runs. The mean

Fig 2 Mean (12 patients) lateral distribution of deposited particles across right lung after inhalation for control, placebo, and drug runs. Column heights are means of radioactive counts for serial traverses, expressed as percentages of patient's total count for that lung. six-hour retention values are in accord with theo mean penetration indices-that is, the greater the penetration index $(0.75$ for the drug) the greater $>$ the six-hour retention value and vice versa, theo smaller the penetration index $(0.41$ for the control $)$ क the smaller the six-hour retention value.

Figure 4 shows the 12 individual paired differ- -6 ences for the amount of radioaerosol retained at: six hours as a percentage of that initially depositedo in the lungs between $(a)$ control and drug runs and (b) placebo and drug runs. The mean $( \pm \mathrm{SD}) \%$ retentions were $62( \pm 21) \%, 65( \pm 22) \%$, and $68 \frac{\mathrm{O}}{\mathrm{D}}$ $( \pm 17) \%$ for the control, placebo, and drug runs $\cong$ respectively. There was no statistically significant $\overrightarrow{\overrightarrow{0}}$ difference $(P>0 \cdot 10)$ between any of the three runs. $\exists$ A comparable analysis at two and four hours showed the same result.

SUBJECTIVE ASSESSMENT, COUGH, AND SPUTUM DATA

The diary cards kept by the patients showed no difference in the severity of breathlessness during

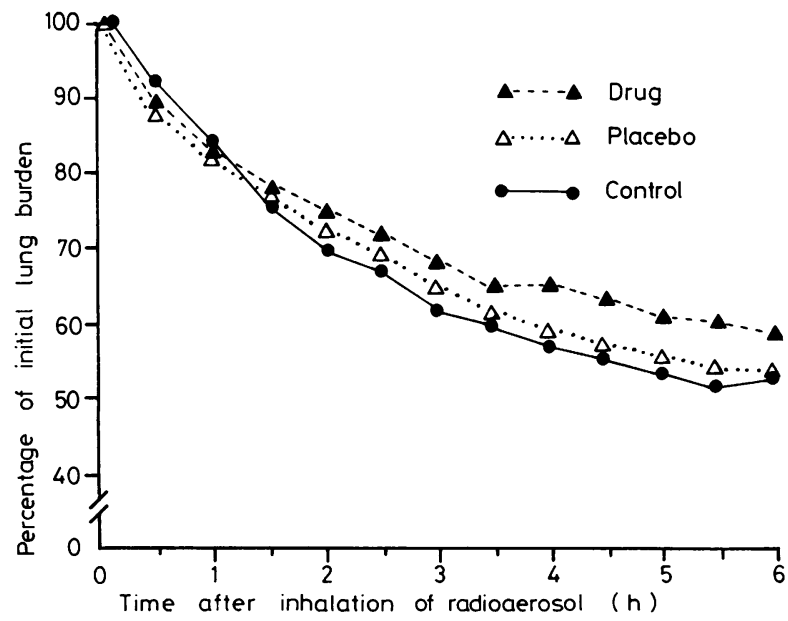

Fig 3 Mean whole lung clearance curves (for 12 patients) for drug, placebo, and control runs. 


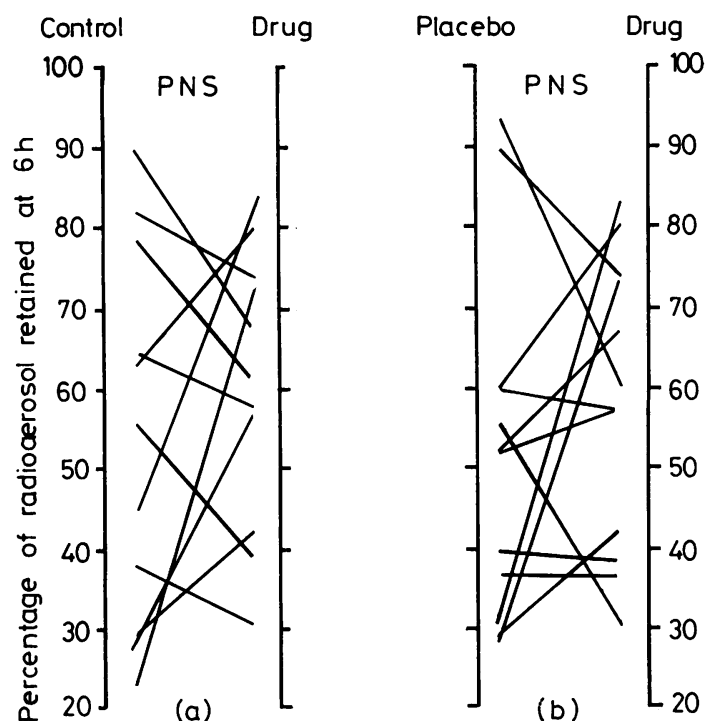

Fig 4 Individual paired differences (12 patients) for amount of radioaerosol retained at six hours as a percentage of that initially deposited in lungs between (a) control and drug runs and (b) placebo and drug runs.

the (a) day-time and $(b)$ night-time between any two of the three weekly periods before the clearance measurements. Further, the quantity of sputum produced during these periods, as judged by the patients, did not differ.

Table 3 gives the mean \pm SD number of coughs and the sputum weight, radioactive content and specific activity (radioactive content/unit weight) observed during the six-hour clearance measurement periods. There was no significant difference for any of the variables between any two trial periods, with the exception of the sputum weight, which was significantly less in the drug than the control $(\mathrm{P}<0.05)$ or placebo $(\mathrm{P}<0.02)$ periods.

Table 3 Mean $\pm S D$ for 12 patients of number of coughs and sputum weight, radioactive content, and specific activity observed during the six-hour clearance measurements

\begin{tabular}{lllll}
\hline & $\begin{array}{l}\text { No of } \\
\text { coughs }\end{array}$ & $\begin{array}{l}\text { Sputum } \\
\text { weight }(g)\end{array}$ & $\begin{array}{l}\text { Sputum } \\
\text { radioactive } \\
\text { content 10 } \\
\text { gamma } \\
\text { counts }\end{array}$ & $\begin{array}{l}\text { Sputum } \\
\text { specific } \\
\text { activity } \\
10^{3} \text { gamma } \\
\text { counts } \text { g }^{-1}\end{array}$ \\
\hline Control & $49 \pm 34$ & $7 \cdot 5 \pm 8 \cdot 5 \dagger$ & $404 \pm 476$ & $48 \pm 30$ \\
Placebo & $45 \pm 26$ & $8 \cdot 5 \pm 12 \cdot 1^{*}$ & $378 \pm 496$ & $34 \pm 33$ \\
Drug & $41 \pm 30$ & $5 \cdot 1 \pm 9 \cdot 0 \dagger^{*}$ & $211 \pm 292$ & $47 \pm 67$ \\
\hline
\end{tabular}

Differences between clearance measurements: ${ }^{*} \mathrm{P}<0.02, \quad \dagger \mathrm{P}<0.05$.

\section{Discussion}

While one recent study (Chopra and Elam, 1978) claims enhancement of mucociliary transport rates in dogs after administration of atropine, others have shown impairment of clearance of secretions from the human lung by the anticholinergic agents hyoscine (Pavia and Thomson, 1971) and atropine (Yeates et al, 1975; Annis et al, 1976; Foster et al, 1976). The impairment of the clearance is attributed either to the drying of secretions (Lopez-Vidriero et al, 1975) or impairment of ciliary beat (Corrsen and Allen, 1959). It may of course be due to a combination of these two effects. This property of impairing clearance of secretions led to the anticholinergic drugs, the bronchodilating effects of which have been known for many years (Goodman and Gilman, 1940), being considered unsuitable for the relief of airway obstruction. Since secretions may add to airflow obstruction (Cochrane et al, 1977), retention is undesirable.

Ipratropium bromide is a synthetic anticholinergic agent, developed specifically to relieve airways obstruction by bronchodilatation, but to be without the undesirable side effects of other anticholinergic drugs (Engelhardt and Klupp, 1975). Using isolated canine airways preparations, Iravani and Melville (1975) noted that ipratroprium bromide exhibited only a mild depressant effect on ciliary beat frequency, which was not doserelated. The bronchodilator action of ipratropium bromide in bronchitic patients, without any change in volume or rheology of secretions, has been reported by several workers (Krieger and Reitberger, 1975; Puchelle and Uffholtz, 1975; Stresemann, 1975). Francis et al (1977) showed significant bronchodilatation using the whole body plethysmograph after the administration of this agent to 12 normal subjects, in single doses up to four times the recommended therapeutic dose (that is, $4 \times 40 \mu \mathrm{g}$ ), with no impairment of mucociliary clearance. In an earlier study on patients with mild obstructive bronchitis and healthy volunteers Matthys et al (1975) using a similar technique to that used here also reported no impairment of mucociliary clearance after bronchodilatation with ipratropium bromide. Their results are to some extent questionable since the drug $(0.1 \mathrm{mg})$ was nebulised with sodium chloride solution. Any possible impairment of lung clearance attributable to the drug could have been reversed by the inhalation of the saline aerosol (Pavia et al, 1977c, 1978; Wood et al, 1977).

The purpose of the present study was to ascertain the effect of ipratropium bromide on the 
clearance of lung secretions, after its administration over a period of one week to a group of patients with reversible airways obstruction.

The bronchodilator action of the drug in these patients was shown by the increase of the lung function indices after its administration in the two-hour pilot study, and by the increase in the PEFRs recorded by the patients in their diary cards during the drug treatment period compared with the control and placebo periods. The increase in the lung function indices noted on the mornings of the drug clearance measurement days probably reflects the action of the last dose administered about one hour previously, as opposed to an improvement attributable to the long-term use of the drug.

The site of deposition of inhaled aerosols in the human lung depends on (1) the physical properties of the aerosol (Lippmann and Albert, 1969; Pavia and Thomson, 1976), (2) the mode of inhalation (Booker et al, 1967; Goldberg and Lourenco, 1973; Pavia et al, 1977a), and (3) lung function (Thomson and Short, 1969; Lippmann et al, 1970; Goldberg and Lourenco, 1973; Thomson and Pavia, 1974; Dolovich et al, 1976). Since in this study (1) and (2) were kept constant, the enhanced penetration of the radioaerosol towards the periphery in the drug runs is due to the improvement in lung function (Pavia et al, 1977b). We believe this is the first time the bronchodilating action of a drug has been shown by a method other than orthodox pulmonary function tests. Possibly the radioaerosol method might prove to be a more sensitive measure of bronchodilatation than such tests; the mean percentage increases in $\mathrm{FEV}_{1}$, PEFR, and penetration index after the period of administration of the drug compared with the control period were $38 \%, 30 \%$, and $109 \%$ respectively.

The percentage of radioaerosol remaining in the lungs at six hours, measured by whole lung counts, reflects to some extent the alveolar deposition (Thomson and Short, 1969; Foord et al, 1977). The proportions of radioaerosol present in the lungs at this time for the drug, placebo, and control runs is in agreement with the penetration index (Pavia et al, 1977a) - that is, for the measurement after the drug, the higher the penetration index the higher the mean six-hour retention, and vice versa for the control measurements with the placebo being intermediate. It is interesting to note that, despite the increased transfer path for the deposited radioaerosol along the ciliated (conducting airways) in the drug run, because of the increased penetrance the mean rate of clearance was no different to that of the placebo or control runs.

In conclusion, the results show that therapeutic $\frac{\bar{\omega}}{\bar{D}}$ doses of ipratropium that cause bronchodilatation $\stackrel{\mathbb{D}}{\Omega}$ have no apparent effect on the clearance of secretions from the human lung.

We thank Miss $\mathbf{R}$ Brownbill for technical help, Dr G A Cox for advice, and Boehringer Ingelheim Ltd for supplying the drugs and financial support.

\section{References}

Annis, P, Landa, J, and Lightiger, M (1976). Effects of atropine on velocity of tracheal mucus in 을 anesthetised patients. Anaesthesiology, 44, 74-77.

Booker, D V, Chamberlain, A C, Rundo, J, Muir, \ D C F, and Thomson, M L (1967). Elimination of 5 micron particles from the human lung. Nature, 215, 30-33.

Chopra, S K, and Elam, D (1978). Effect of atropine $\vec{\theta}$ on mucociliary transport velocity. American Review of Respiratory Disease, 117, (suppl), 226.

Cochrane, G M, Webber, B, and Clarke, S W (1977). Effects of sputum on pulmonary function. British Medical Journal, 2, 1181-1183.

Corssen, G, and Allen, C R (1959). Acetylcholine: its significance in controlling ciliary activity of human $\mathbb{D}$ respiratory epithelium in vitro. Journal of Applied $\overrightarrow{\vec{O}}$ Physiology, 14, 901-904.

Cotes, J E (1975). Lung Function, 3rd edn. Blackwell, Oxford.

Dawson, H, Douglas, R B, Pavia, D, Reeves, E, Short, M D, and Thomson, M L (1971). An inexpensive automatic two-detector lung scanner. Physics in Medicine and Biology, 16, 691-692.

Few, J D, Short, M D, and Thomson, M L (1970). Preparation of ${ }^{80 \mathrm{~m}} \mathrm{Tc}$ labelled particles for aerosol studies. Radiochemical and Radioanalytical Letters, 5, 275-277.

Engelhardt, A, and Klupp, H (1975). The pharma- 웅 cology and toxicology of a new tropane alkaloid derivative. Postgraduate Medical Journal, 51 (suppl 을 7), 82-85.

Dolovich, M B, Sanchis, J, Rossman, C, and New- o house, M T (1976). Aerosol penetrance: a sensitive N index of peripheral airways obstruction. Journal N of Applied Physiology, 40, 468-471.

Foord, N, Black, A, and Walsh, M (1977). Pulmonary deposition of inhaled particles with diameters in the range 2.5 to $7.5 \mathrm{um}$. In Inhaled Particles IV, edited by W H Walton, p 137. Pergamon Press, ? Oxford.

Foster, W M, Bergofsky, E H, Bohning, D E, Lippmann, M, and Albert, R E (1976). Effect of adrenergic agents and their mode of action on $\vec{D}$ mucociliary clearance in man. Journal of Applied Physiology, 41, 146-152.

Francis, R A, Thomson, M L, Pavia, D, and Douglas, R B (1977). Ipratropium bromide: mucociliary 
clearance rate and airways resistance in normal subjects. British Journal of Diseases of the Chest, 71, 173-178.

Goldberg, I S, and Lourenco, R V (1973). Deposition of aerosols in pulmonary disease. Archives of Internal Medicine, 131, 88-91.

Goodman, L, and Gilman, A (1940). The Pharmacological Basis of Therapeutics, p 464. Macmillan, New York.

Iravani, J, and Melville, G N (1975). Ciliary movement following various concentrations of different anticholinergic and adrenergic bronchodilator solutions in animals. Postgraduate Medical Journal, 51 (suppl 7), 108.

Krieger, E, and Reitberger, U (1975). Sputum rheology following treatment with Sch $1000 \mathrm{MDI}$ and orciprenaline MDI. Postgraduate Medical Journal, 51 (suppl 7), 108.

Lippmann, M, and Albert, R E (1969). The effect of particle size on the regional deposition of inhaled aerosols in the human respiratory tract. American Industrial Hygiene Association Journal, 30, 257275.

Lippman, M, Albert, R E, and Peterson, $\mathrm{H} \mathrm{T}$, jun (1970). The regional deposition of inhaled aerosols in man. In Inhaled Particles 111 , edited by $\mathrm{W} \mathrm{H}$ Walton, p 105. Unwin, Old Woking, Surrey.

Lopez--Vidriero, M T, Costello, J, Clark, T J, Das, H, Keal, E E, and Reid, L (1975). Effect of atropine on sputum production. Thorax, 30, 543-547.

May, K R (1949). An improved spinning top homogenous spray apparatus. Journal of Applied Physics, 20, 932-938.

Matthys, H, Müller, M, Konietzko, N, and Adam, W E (1975). Tracheo-bronchial clearance studies with and without Sch 1000 using $99 \mathrm{~m}$ technetium sulphate $\left({ }^{99 \mathrm{~m}} \mathrm{Tc}\right)$ particles. Postgraduate Medical Journal, 51 (suppl 7), 108.

Medical Research Council (1965). Definition and classification of chronic bronchitis for clinical and epidemiological purposes. Lancet, 1, 775-779.

Pavia, D, and Thomson, M L (1971). Inhibition of mucociliary clearance from the human lung by hyoscine. Lancet, 1, 449-450.

Pavia, D, and Thomson, M L (1976). The fractional deposition of inhaled 2 and 5 micron particles in the alveolar and tracheobronchial regions of the healthy human lung. Annals of Occupational Hygiene, 19, 109-114.

Pavia, D, Thomson, M L, and Shannon, H S (1977a). Aerosol inhalation and depth of deposition in the human lung: the effect of airway obstruction and tidal volume inhaled. Archives of Environmental Health, 32, 131-137.

Pavia, D, Thomson, M L, Clarke, S W, and Shannon, H S (1977b). The effect of lung function and mode of inhalation on penetration of aerosol into the human lung. Thorax, 32, 194-197.

Pavia, D, Thomson, M L, and Clarke, S W (1977c). Enhancement of bronchial clearance by hypertonic saline aerosol in chronic bronchitis. Thorax, 32, 647-648.

Pavia, D, Thomson, M L, and Clarke, S W (1978). Enhanced clearance of secretions from the human lung after the administration of hypertonic saline aerosol. American Review of Respiratory Disease, 117, 199-203.

Poppius, H, Salorinne, Y, and Viljanen, A A (1972). Inhalation of a new anticholinergic drug, Sch 1000 , in asthma and chronic bronchitis: effect on airway resistance, thoracic gas volume, blood gases and exercise-induced asthma. Bulletin de Physiopathologie Respiratoire, 8, 643-653.

Puchelle, E, and Uffholtz, H (1975). Sputum viscoelasticity following administration of Sch $1000 \mathrm{MDI}$. Postgraduate Medical Journal, 51 (suppl 7), 109.

Snedecor, G W, and Cochran, W C (1968). Statistical Methods, 6th edn, p 128. Iowa State University Press, Ames, Iowa.

Stresemann, E (1975). Total airways resistance $\left(R_{1}\right)$, sputum volume and rheology in patients with chronic bronchitis following treatment with Sch 1000 MDI and placebo. Postgraduate Medical Journal, 51 (suppl 7), 110.

Thomson, M L, and Short, M D (1969). Mucociliary function in health, chronic obstructive airway disease, and asbestosis. Journal of Applied Physiology, 26, 535-539.

Thomson, M L, and Pavia, D (1973). Long-term tobacco smoking and mucociliary clearance from the human lung in health and respiratory impairment. Archives of Environmental Health, 26, 86-89.

Thomson, M L, Pavia, D, and McNicol, M W (1973). A preliminary study of the effect of guaiphenesin on mucociliary clearance from the human lung. Thorax, 28, 742-747.

Thomson, M L, and Pavia, D (1974). Particle penetration and clearance in the human lung. Archives of Environmental Health, 29, 214-219.

Wood, R E, Horowitz, J, and Mancini, N (1977). Effect of saline aerosol on tracheal mucociliary transport in normal subjects and patients with cystic fibrosis. American Review of Respiratory Disease, 115 (suppl), 295.

Yeates, D B, Aspin, N, Levison, H, Jones, M T, and Bryan, A C (1975). Mucociliary tracheal transport rates in man. Journal of Applied Physiology, 39, 487-495.

Requests for reprints to: Dr D Pavia, Department of Thoracic Medicine, Royal Free Hospital, London NW3 2QG. 